\title{
An Exploration on the Transformation and Development Path of Specialty Clusters in Normal Universities
}

\author{
Xinhua XU, Song LIN \& Wenshan CHENG \\ College of Educational Information \& Technology, Hubei Normal University, Hubei Huangshi 435002, P.R. \\ China
}

\author{
Hongying GAO \\ Hubei Normal University Library, Hubei Normal University, Hubei Huangshi 435002, P.R. China \\ Min LIU \\ College of Foreign Studies, Hubei Normal University, Hubei Huangshi 435002, P.R. China
}

\begin{abstract}
Under the policy background of undergraduate transformation and development, the transformation and development of specialties is a strategy of partial transformation for local undergraduate normal universities. The electronic information specialty in Hubei Normal University has made valuable preliminary exploration in the fusion of production and education, university-enterprise cooperation, innovation and entrepreneurship, the practical training base and the construction of "double-qualified teacher", such as the founding of "project studio", "science and technology enterprise incubator" and "the studentowned companies ". These measures have laid a solid foundation for the priority transformation and development of the specialty clusters, and it can be used as a reference for the transformation and development pilot of local undergraduate normal universities.
\end{abstract}

KEYWORD: The transformation of specialty; University-enterprise cooperation; The fusion of production and education; Project Studio; The student-owned companies

\section{THE BACKGROUND OF THE UNDERGRADUATE TRANSFORMATION}

\subsection{The top-level design to promote the development of vocational education reform}

In May 2014, the release of The State Council's Decision about Accelerating the Development of Modern Vocational Education means the completion of top-level design to promote the development of vocational education reform in the new period, and emphasizes "speeding up the construction of modern vocational education system", "establishing undergraduate vocational education" and "vocational education must be classified advancement". In June, the Ministry of Education and six ministries jointly issued The Modern Vocational Education System Construction Plan (2014-2020), and further proposed to encourage the establishment of application technological universities.

\subsection{The essence of the undergraduate transformation and development}

The essence of the transformation is to establish talents cultivation model according to the goals, and vocational education personnel training mode should pay more attention to the development of professional quality and ability.
2 THE TRANSFORMATION OF NON-NORMAL SPECIALTY CLUSTERS--THE TRANSFORMATION STRATEGY OF LOCAL UNDERGRADUATE NORMAL UNIVERSITIES

\subsection{Following "four principles"}

Transformation of pilot is of great significance to adjust the structure of education in universities and the location. Pilot universities should follow" four principles", namely, turning the way of education to serving local economic and social development, to the fusion of production and education, to university-enterprise cooperation, to training application and technical talents, and to enhancing students' abilities of employment and entrepreneur.

A number of local undergraduate colleges and universities developed from normal colleges, so a lot of normal universities need transformation. On the premise of following the guiding of "four principles", the local pilot undergraduate normal universities can adopt flexible strategies, maintain its normal (teachers) education of subjectivity, and make sure the transformation based on good engineering professional pilot (cluster) transformation, and gradually expand, namely" first trial, then the promotion, first local, then the whole". 


\subsection{The Transformation Pilot Strategy}

Normal universities have certain characteristics and advantages, and years' of school-running history and rich experience. These must be kept, and their subjectivity must be unshakable. But the normal and non-normal enrollment rate can be cut appropriately. The existing teaching programs must be done properly on the premise of maintaining the statuesque temporarily, but attention must be paid to the engineering professional cluster transformation, which is closely combined with the local economy and society, and explore the transformation and development path for the local normal colleges of non-normal professional transformation of cluster development path, in preparation for the overall transformation.

\section{THE EXPLORATION ON THE TRANSFORMATION AND DEVELOPMENT PATH OF SPECIALTY CLUSTERS}

The transformation of local undergraduate colleges and universities should achieve the transformation of concept and model. Schooling concept includes: firstly, colleges and universities should link school running with economic and social development. Secondly, applied talents should be cultivated with a view to employment and professional development of colleges. Thirdly, the survival and development of colleges and universities is becoming more and more restricted by economic and social demand and supply.

For the transformation and development path of specialty clusters, the specialty cluster of electronic information in Hubei Normal University has exploited a lot as follows:

\subsection{Seeking for cooperation between university and enterprise and establishing the committee of specialty cluster transformation development and teaching instruction}

Our cooperation between university and enterprise has certain basis. In order to adapt to the needs of transitional development, we have deepened the cooperation with industries and enterprises and established close relationship with many industries and enterprises, such as Huangshi Municipal Commission of Economy and Information Technology, Huangshi Communications Authority, Huangshi digital mall, Hengyingchao Science and Technology Ltd. in Hubei, and conducted an indepth corporate research about personnel training elements including types of personnel training, post vocational skills requirements, curriculum provision, practice curriculum system, professional certificate, special credit and training base concerning electronic information, follow-up discussion, amending and writing of this training program, and absorbs the full participation of members in industries and enterprises in order to be observant and alert instead of teachers' acting blindly.

To enhance the mechanism of industries and enterprises' participation in educational transformation, the specialty cluster transformation development and teaching instruction committee has been established, in which among 19 members, 9 members come from local government and industries, employers and other partners, accounting for $47 \%$.

\subsection{Combining production and education, and focusing on cultivating students' practical ability, innovation and entrepreneurship ability and professional skills}

As early as in 2006, we realized the malpractice of emphasizing theory but underestimating practice in talent training, then we abandoned the traditional practice teaching mode and established "project studio system" with features of modern apprenticeship to cultivate students' practical ability, innovation and entrepreneurship ability and vocational skills. Combining studio system with project system, "taking the project as the carrier, the studio as a platform" and taking the best points of the two sides can not only highlight the high efficiency of project management mechanism, but also bring fresh and practical content to studio, develop the engineering advantage of doubleprofessionally-titled teachers and cultivate preparatory engineer with strong manipulative ability and high creativity. Faculty advisers are recruited and selected from enterprises and universities, who are in the charge of one or many teachers with strong professional ability and corporate background, guide students to use real or virtual engineering project as carrier and implement activities including project developing, science and technology inventions making, discipline competition, application of science and technology project, Challenge Cup training and college students' innovative and entrepreneurial ability. Project studio has helped to provide engineering project development for students majoring in electronic information, to provide students platform to learn, communicate and grow up as well as to show their talents, to enhance professional core ability and engineering practice ability, and to cultivate applied technology and skill talents enjoying great popularity in enterprises, realizing the seamless joint work post.

The "mentoring system" is carried out interiorly among students, worshipping "let those who can serve as teachers", and proselytizing instructs dispelling doubt. The advanced help the junior and the seniors help the freshmen, cultivating students' professional ability and comprehensive quality in 
initiative corporation practice; fostering talents from early undergraduate years and following scientifically progressive and grading training route and forming a complete talent team in order to make everyone to be applied, inter-disciplinary and innovative talent who is good at many things and expert in one.

So far, there have been many "project studios", such as PHP Special Website, Electronic Design, FPGA Design, Java Load Angle, ICT Information Communication, DSP Soft- and Hardware Development, Audio Technique, Two-Dimensional Animation, Three- Dimensional Animation, Multimedia Courseware, After Effects, Digital Media. After many years of operation and cultivation of school leadership, great achievements have been made in the project studio. Students from these studios get generally quick adaptation and strong technical capacity. So far, more than 100 graduates have held the post of CTO (Chief Technology Officer), PM (Project Manager), Engineering and Technical Backbone, which speaks volumes for the success of "project studio"--this kind of apprenticeship combines the production and education as well as talents cultivating model of practical teaching.

\subsection{Hatching Students-owned Companies and cultivating the consciousness and competence of innovation and entrepreneurship}

We pay attention to the organic combination of professional education and entrepreneurship education so as to help students not only to master entrepreneurship-needed skills but also to have entrepreneurial sense and entrepreneurial competence and it is essential to cultivate innovative consciousness throughout the entrepreneurship education. Contemporary institutions of higher learning must inject innovative and entrepreneurial elements into the connotation, regarding education with the aim to cultivate innovative consciousness as important talent-cultivating mode, focusing on cultivating innovative consciousness, entrepreneurial quality and entrepreneurial culture to adapt to the era of knowledge economy and shaping students' independent innovative spirit and entrepreneurial personality.

With years' accumulation of experience, we decide to build upgraded version of "project studio". We found student-oriented companies, accept the outside projects and assume sole responsibility for its profits or losses . The companies hire experienced talents as counselors. In order to better serve "Students-owned Companies", Huangshi Jurong Science and Technology Business Incubator Ltd has been set up with the support of Hubei Normal University, which has a high-qualified expert management group and a 2000 square meters' administrative area, including the meeting rooms and the well-equipped laboratories.

These incubators mainly provide an innovative and entrepreneurial platform for large and medium hi-tech corporations so as to offer hi-tech corporations in the district with services like project application, project training, project financing, patent filing, achievement appraisal, legal consulting, financial audit, production exhibition, marketing plan, enterprise strategy, management consultancy, talent introduction, hi-tech enterprises' review and identification, and further promote the regional economic development of Huangshi.

With the guidance of the company and on the basis of the studio, we have set up Huangshi Tianyu Electronic Technology Ltd, Huangshi Weidong Graphic Design Ltd, Huangshi Innovation Network Technology Ltd, Huangshi Yidong Advertisement Ltd, Huangshi Weiying Cartoon Ltd, Huangshi Ugly Duckling Electronic Design Ltd,HuangshiRuiyi Multi-medium PowerPoint Ltd, Huangshi Network Ltd, Huangshi Sound Equipment Ltd, Huangshi Ltd, Huangshi Network Ltd, Huangshi Runhui Electronic technology Ltd, Huangshi Luoping E-commerce Ltd.

We expect that the students-owned companies make job creators out of students, not just common job seekers.

\subsection{Guaranteeing Practical Teaching Needs and Constructing Practical Training Bases}

In accordance with the principles of advancement, practical applicability, sharing and professionalism and adhering to constructive thought of combination with the interior and the exterior, fusion of production and education, resource sharing and rational layout, we have basically built a skillstraining base integrating functions such as practical teaching, professional practice, training, technical training services and verification of professional technical ability.

The construction of the practical training base pays attention to exert the enterprise's dominant role, arouses the initiative and enthusiasm of school management and the sense of social responsibility and establishes new double subject system of school management so as to achieve deep cooperation between the school and the enterprise.

We should innovate win-win and complementary mechanism of school-enterprise cooperation and various cooperation patterns. The new mechanism meets the corporation's win-win expectation and promotes sustainability as well as cooperation's strata and connotation. Take the case of information engineering specialty, we cooperate with Huangshi Digital City to build the practical training base of "computer assembly and maintenance" and Hubei branch of Hengying Super Technology Ltd provides the "Intelligent Electronics and Embedded 
Manufacture" training base. We also have a provincial experiment teaching demonstration center of the education information technology and a provincial education information virtual laboratory. To support specialization, the school contributes money to building computer, network and integration, sound equipment, embedment and threedimension animation laboratories. The practical training class hour accounts for $40 \%$ of the total class hour and students take part in the practical training for one year. The construction of the practical training base is the material basis, which carries out the new scheme's technical skills system.

\subsection{Constructing the "Double-qualified Teacher" Team}

To construct the "double-qualified teacher" team, for one, we should improve structure, that is to introduce "skillful craftsmen" and technical experts as part-time teachers from the cooperative enterprise, for the other, we should cultivate double qualified teachers from inside through such forms as corporate practice with determine posts, professional training, professional development. The first way is quick and introduces original elements of enterprise technologies, which is contributive to transformation and awareness raising of specialized teachers engineering technology skills. Schools can also establish practical teaching posts such as to appeal outstanding corporate experts. The second way requires longstanding and unremitting cultivation. It is necessary for the school to introduce coherent incentive measures and policies, which are in favor of salaries, promotion and spirit encouragement. These will encourage professional teachers to enter enterprises to engage in projects and to strive to make technological breakthrough, so that they can rapidly grow up to bipolar teachers who are competent to meet the needs of the professional (cluster) transformation.

Our specialty cluster now has 120 professional teachers, including 28 teachers with a higher theoretical level and strong practical capabilities and 26 outstanding enterprise technicians as part-time teachers, which improve the whole construction of the professional teaching force. In the recent five years, teachers have been annually selected and sent to training institutions to receive training in the summer vocation (4 professional teachers have been sent to Wuhan Yutian network Technology Ltd to participate in the engineer certification train of Huawei, Oracle, Red Hat and Cisco) and 20 young teachers have been annually sent to practice in enterprises in the recent two years. In addition, this year, our school has established the vocational skills evaluation center and 10 teachers of electronic information specialty have taken part in the evaluation staff training of multiple vocations, which are effective measures to strengthen the construction of bipolar teachers.

\section{CONCLUSION}

Since 2006, expedition has been made by electronic information specialty in cultivating professional talents, in line with the guidance of education authorities, which demonstrates our action is rational. We can carry out specialization on the basis of that and also regard it as the decision-making reference of the normal college transformation.

\section{ACKNOWLEDGEMENT}

The research work was supported by the Hubei Province Education Science "Twelfth Five Year Plan" project (Grant No. 2012B329) and Hubei Normal University Talents Project (Grant No. 2014F0330).

\section{REFERENCES}

[1] Luhui, X. 2014. How to Transformate and Develop for local undergraduate universities. China education newspaper, version10, On Oct 20.

[2] Martin, Trow. 1999. The problems in the transition from elite to mass higher education. Foreign institutions of higher education information 27(2):10-13

[3] Zhengwen, Z. 2010. Entrepreneurship education mode should be for the purpose of innovation consciousness. China education newspaper, Version 3, On June 3. 